\title{
Newly observed phraseological units with noun forms of modal verbs
}

\author{
Ai Inoue
}

Received: 29 April 2014/Accepted: 6 December 2014/Published online: 6 January 2015

(C) Springer Berlin Heidelberg 2014

\begin{abstract}
This study approaches newly observed phraseological units (PUs) in contemporary English from semantic and corpus perspectives. The discussion focuses on PUs shoulds and oughts, oughts and musts, and shoulds and musts. One of the interesting phenomena observed in contemporary English is the appearance of the noun forms of modal verbs. Examples include should, shoulds, oughts, and ought to's, which resemble must. Adopting a quantitative perspective based on contemporary English corpora, I argue that not all modal verbs evolve into nouns and that past noun forms (e.g., could, should) and plural forms (e.g., shoulds, oughts) appear most frequently in contemporary English. I also demonstrate that plural forms (e.g., shoulds, oughts, and ought to's) function as "obligations" because of their semantic analogy to must. This function reflects the essential functions of each modal verb. Regardless of whether they are singular or plural, the noun forms of modal verbs also serve meta-linguistic functions, as they raise awareness of the essential functions of each modal verb. Using examples from corpora, I demonstrate that PUs consisting of the noun forms of modal verbs such as shoulds and oughts, oughts and musts, and shoulds and musts are used more commonly than are the separate noun forms. The results also indicate that the functions of PUs differ from those of must (i.e., obligation) and that each PU retains its own function, which is derived from its components.
\end{abstract}

Keywords Phraseology · Phraseological units · Noun forms of modal verbs · Contemporary English $\cdot$ Semantic and corpus perspective $\cdot$ Meta-linguistic function

\footnotetext{
A. Inoue $(\bowtie)$

National Defense Academy of Japan, Yokosuka, Kanagawa, Japan

e-mail: narudo24@hotmail.com
} 


\section{Introduction}

Contemporary English changes rapidly. Studies by Mair and Leech (2006: 320) and by Leech and colleagues (2009) draw on data obtained from corpora ${ }^{1}$ to summarize English grammatical changes observed in contemporary English over recent decades. Studies on changes in contemporary English focus largely on the description of English lexical changes and grammaticalization. Little attention has been paid to the demonstration of actual behaviors involving newly produced phrases (generally defined as frequently used combinations consisting of at least two words). Although English dictionaries that have recently been published in Europe and the US attempt to describe and explain newly observed phrases, such descriptions and explanations are obviously far removed from the actual behavior of these phrases.

Phraseology, the study of phrases, is based on the idea that phrases play essential roles in allowing language activity to proceed smoothly. When reading a newspaper, we easily find a large number of phrases consisting of words with which we are familiar. We feel as if we understand their meanings, even if they are not described in dictionaries. Nevertheless, we do not fully understand their meanings. Such phrases are ubiquitous in language, constituting a significant resource for communication. They can also help learners of English as a Foreign language, make their English as fluent as that of native speakers. Most previous studies on phrases have not provided any comprehensive discussion of such phrases. When they are addressed, the discussion usually centers on a single phrase.

For example, Biber et al. (1999) solely cite phrases called lexical bundles such as do you want me to, you want me, I think it's a, and in the case of in the LSWE Corpus. ${ }^{2}$ Lexical bundles are referred to as lexical phrases in a dictionary and are

\footnotetext{
(a) A tendency to regularize irregular morphology (e.g., dreamed $\rightarrow$ dreamt).

(b) Revival of the "mandative" subjunctive, probably inspired by formal US usage (we demand that she take part in the meeting).

(c) Elimination of shall as a future marker in the first person.

(d) Development of new, auxiliary-like uses of certain lexical verbs (e.g., get, want—cf. e.g., the way you look, you wanna/want to see a doctor soon).

(e) Extension of the progressive to new constructions, including the modal, present perfect, and past perfect passive progressive (the road would not be being built/has not been being built/had not been being built before the general elections).

(f) Increase in the number and types of multi-word verbs (phrasal verbs, have/take/give a ride, etc.).

(g) Placement of frequency adverbs before auxiliary verbs (even when no emphasis is intended-I never have said no).

(h) Do-support for have (have you any money? and no, I haven't any money $\rightarrow$ do you have/have you got any money? and no, I don't have any money/haven't got any money).

(i) Demise of the inflected form whom.

(j) Increasing use of less instead of fewer with countable nouns (e.g., less people).

(k) Spread of the s-genitive to non-human nouns (the book's cover).

(1) Omission of the definite article in certain environments (e.g., renowned Nobel laureate Derek Walcott).

(m) "Singular" they (everybody came in their car).

(n) Like, same as, and immediately used as conjunctions.

(o) A tendency towards analytical comparatives and superlatives (politer $\rightarrow$ more polite).
}

${ }^{2}$ LSWE Corpus is the Longman Spoken and Written English Corpus. It contains over 40 million words of text, providing a sound basis for reliable analysis of grammatical patterns in different registers: conversation, fiction, news, and academic prose (Biber et al. 1999: 24). 
defined as "semi-preconstructed phrases that constitute single choices, even though they might appear to be analysable into segments" (Sinclair 1991: 110). Biber et al. (1999) show what kinds of lexical bundles are used in two registers: academic prose and conversation. We can easily predict the whole meaning of lexical phrases.

However, there has been no systematic study of such phrases, which consist of familiar words and are hard to understand. Although native speakers of English are apparently good at finding and understanding them, they have difficulty recognizing them, as their use in daily conversation is frequent, but unconscious. This study therefore focuses on phrases that have been overlooked to date and that have yet to be understood correctly.

One interesting linguistic phenomenon in contemporary English involves the use of the noun forms of auxiliary verbs (e.g., oughts, shoulds). From a semantic perspective, the noun forms of auxiliary verbs are used in a meta-linguistic manner that reveals the core functions of each auxiliary verb. Some of the noun forms of auxiliary verbs are joined together to operate as phraseological units (e.g., shoulds and oughts and shoulds and musts).

In the interest of advancing the present state of phraseology, this study describes the actual behaviors of newly observed phrases consisting of two noun forms of auxiliary verbs (e.g., shoulds and oughts, and shoulds and musts), drawing upon data obtained from corpora. The basic argument is that the meanings of phrases are closely related to their syntactic patterns. The study also demonstrates that newly observed phrases consisting of two noun forms of auxiliary verbs serve a unique grammatical function as nouns. In other words, the phrases formed by two function words behave like a content word. This reflects a trend opposite to that of grammaticalization: degrammaticalization.

\section{Phraseology}

\subsection{What is phraseology?}

In general, phraseology is defined as "(A) choice of arrangement of words and phrases; style of expression; the particular form of which characterizes a language, author, work, etc." (Shorter Oxford Dictionary, 6th edition; SOD ${ }^{6}$ ). Phraseology can also refer to unique forms of English (as compared to other languages). Examples include Hemingway's phraseology (e.g., with regard to the characteristics of expressions and stylistics) and legal phraseology (i.e., words, terms, and phrases only used in legal discourse).

As one of several fields of linguistic research, phraseology covers collocations, ${ }^{3}$ idioms, ${ }^{4}$ multi-word expressions, ${ }^{5}$ and formulae. ${ }^{6}$ Phraseological research deals

\footnotetext{
${ }^{3}$ Collocations are defined as "word-combinations that have predictability and collocational range such as deciduous tree, rancid butter" (Inoue 2007: 105).

4 Many scholars define idioms from the viewpoint of semantic non-transparency or non-compositionality as whole meanings of idioms that cannot be derived from each component and that have strong semantic associations between components (e.g., kick the bucket and spill the beans).

5 Multi-word expressions are literally defined as phrases consisting of at least two words (e.g., you know what, here we go, here we go again). Unlike idioms, the whole meanings of multi-word expressions are
} 
with them from various perspectives. Burger et al. (2007) classify it into the following research areas at least.

1.

(a) Subject area, terminology and research topics

(b) Semantics of set phrases

(c) Semiotic aspects of set phrases

(d) Set phrases in discourse

(e) Set phrases in types of texts and conversation

(f) Phraseology of literary texts and individual authors

(g) Proverbs

(h) Particular types of set phrases

(i) Set phrases in technical language

(j) Areal aspects of phraseology

(k) Contrastive phraseology and translation

(1) Phraseology in individual languages

(m) Cognitive and psycholinguistic aspects

(n) Language acquisition and language teaching

(o) Phraseolography

(p) Computational linguistic aspects of phraseology

(q) Corpus linguistic aspects of phraseology

(r) Historical phraseology

Also, Burger et al. (2007: XI) mentions that “... today there is a general consensus that phraseology encompasses a very palette of linguistic phenomena and issues". In practice, however, the coverage of phraseology is much wider, extending to include the syntactic patterns of the complementation of a verb, a predicative adjective, or noun. Originally, the combinations of two grammatical categories (e.g., a verb and a preposition) have been referred to as colligation in correspondence to collocation. The scope of phraseology has been expanded to include studies ranging from phrases to colligation. Examples include the types of complementation a verb (e.g., want) has or the semantic relationship between a verb (e.g., look) and a preposition. Phraseologies are thus linguistic research fields that address the actual behaviors of phrases as well as specific linguistic phenomena or irregularities.

Terms used in phraseology include "phraseological unit", "phraseme", "recurrent-word combinations", "fixed expressions", and "idioms". Also, definitions used in phraseological research vary from studies to studies. As stated by Cowie (1998: 4), "in phraseology, as in other fields within linguistics, it is not uncommon for

\section{Footnote 5 continued}

predictable from each component, although they change in accordance with the contexts in which they are used. For example, Inoue (2007) mentions that you know what has various meanings, depending upon the context. These multi-word expressions thus constitute polysemous phrases.

${ }^{6}$ Formulae are fixed expressions (e.g., how are you?). Some are not fully transparent in the semantic sense (e.g., now you're talking and it isn't over until the fat lady sings). 
individual scholars to apply different terms to the same category (or the same term to different categories). I have therefore thought it essential-while not suppressing individual differences - to provide a general framework, in which the terms used by any one individual can be understood in relation to those used by others". The present study adopts the most widespread term: phraseological units (PUs), in phraseological research, PUs, which are defined as repeatedly used strings consisting of at least two words.

\subsection{Why is phraseology important?}

The increasing attention that is being paid to phraseology is due to such factors as the advancement of corpus linguistics, the growing interest in lexicography, the application of phraseology for language education, and the advent of language technology applications such as full text translation, word processing, text mining, etc. The syntactic rules and lexicons mentioned in existing linguistic theories are less suited than phraseology is for explaining the roles that many PUs play in contexts involving the acquisition and use of language. As demonstrated in studies by Cowie (1998) and Howarth (1998), the use of collocations in papers written by native speakers of English differs significantly from that appearing in the academic papers of non-native authors writing in English. The naturalness of a given language thus apparently rests in the use of PUs. It is obviously possible to generate an infinite number of sentences using the syntactic rules and lexicons explained in linguistic theories. Even if they are grammatically correct and semantically congruent, however, there is no guarantee that sentences generated in this manner will possess the characteristic "Englishness" reflected in sentences formed by native speakers. Research in English phraseology focuses on identifying the phrases that constitute Englishness and that help language activities to resemble those of native speakers.

\subsection{Why are PUs important?}

The primary importance of PUs stems from the necessity of effective foreign language education. Consider the following quotation:

2. ... communicative competence is not a matter of knowing rules for the composition of sentences... It is much more a matter of knowing a stock of partially pre-assembled patterns, formulaic frameworks, and a kit of rules, so to speak, and being able to apply the rules to make whatever adjustments are necessary according to contextual demands. Communicative competence in this view is essentially a matter of adaptation, and rules are not generative but regulative and subservient.

Widdowson (1989: 135), also quoted in Willis (2003: 142)

The idea mentioned in (2) differs radically from the fundamental concepts of linguistic theories, which focus on syntax. As stated in (2), patterns or PUs (e.g., 
multi-word expressions or formulae) constitute the heart of a language. Grammatical rules merely play a coordinating role, subordinate to PUs. Consider the following example: there are a lot of people gathering in front of the station. The sentence consists of the syntactic pattern $<$ there are + place adverbial phrase $>$, and formulae $<$ a lot of $>$, $<$ in front of $>$, and $<$ people gather + place adverbial phrase $>$. Grammatical rules (e.g., changing gather into gathering) are used merely to achieve the proper arrangement for the pattern and formulae. This example clearly demonstrates that, instead of grammatical rules, the knowledge necessary for communication concerns a large number of PUs and patterns.

\subsection{Phraseology in dictionaries}

Descriptions of phrases in dictionaries published in Europe and Northern America have been fulfilling ones. However, they are not quantitatively and qualitatively enough because they do not meet the vital requirements for dictionaries: (1) dictionary descriptions must be accurate in minutely explaining the actual behavior of a linguistic phenomenon, (2) dictionary descriptions should validate the prevailing notions of a word or a phrase and ascertain their truth or false, and (3) dictionary descriptions cannot be the overabundance of information about words and phrases too much to meet the diverse needs of dictionary users.

One of the recent trends in English is to combine two prepositions into new complex prepositions (CPs), defined as a word group that functions as a single preposition, such as in at, and in for. In particular, two adverbial particles in and on co-occur with various prepositions and help establish new CPs. For example, $M E D^{2}$ lists new CPs such as in at, in for, in on, on about, and on at. OALD ${ }^{8}$ describes in at, in for, and in with (s.v. in) and on about, on at, and on for (s.v. on). However, we can easily find CPs, which are not described in dictionaries, in contemporary English. In addition, an extensive literature review shows that previous research and English dictionaries do not address this trend. The current situation regarding CPs does not fulfill the requirements for dictionaries.

Inoue (2014) describes newly observed PUs created by combining two prepositions into a $\mathrm{CP}$ such as on against and in to and proposes that be on against and be in to are newly observed PUs in contemporary English, which have not yet been described in previous research or English dictionaries. Data obtained from corpora of present-day English show that on against and in to mainly co-occur with be verbs, and be on against and be in to are also observed.

Same as new CPs, no dictionaries deal with PUs such as shoulds and oughts, oughts and musts, and shoulds and musts, which is the focal point of the study. Advanced English learners might understand their meanings because of the analogy to a must as a noun. However, they would not tell the difference between the three PUs. If they look them up in dictionaries, they would be at a loss and not understand the difference. Hence, the phraseological research in dictionaries should be actively carried out from quantitatively and qualitatively standpoints to improve the current situation. 


\section{Methodology}

\subsection{Theory underlying this study}

The present descriptive study is a concrete examination of linguistic phenomena, which does not depend on any major linguistic theory (e.g., generative grammar). The fundamental thesis for this research is the theory of semantic syntax, which assumes that part of the meaning of a word is closely related to its syntactic characteristics. The reason why the study adopts the theory is that existing linguistic theories are valid only for native speakers of English. Researchers, whose native language is not English, have to use the inductive method which minutely describes and consistently explains linguistic phenomena in order that they interpret the intuition and expressions of native speakers of English. The theory can help the researchers to inquire into the use of English and is deeply rooted in the tradition of studying English in Japan. In addition, it is a continuation of the tradition revised and developed under the influence of various linguistic theories developed in the United States and elsewhere.

\subsection{Data}

This study is based on data obtained from the British National Corpus, WordBanksOnline, and the Corpus of Contemporary American English. As demonstrated by Sampson (2001), the use of a corpus as a database offers three advantages. First, a corpus can be established by collecting and recording both spoken and written language. Therefore, it allows the objectification of data on which research is based. It also facilitates access to spontaneously used data for language research. A second advantage of corpora is that they allow for the verification of research results on demand by third parties. In contrast, data based on human intuition are not objective, as they are accessible only to the researcher, thus preventing their validation by third parties. Research and theories that allow third-party verification are open to the possibility of refutation, which increases their credibility. A final advantage of using a corpus is that it allows researchers whose native language is not English (as is the case with this study) to study English on an equal footing with researchers who speak English as a native language. Research that is based entirely on personal intuition thus largely restricts researchers to the investigation of their own native languages (Inoue 2007: 112f).

\section{Previous research on auxiliary verbs}

The noun forms of auxiliary verbs like musts, shoulds, and oughts are deeply connected to their auxiliary verbs. This section provides an overview of auxiliary verbs. 


\subsection{Descriptions of musts, shoulds, and oughts}

To date, no substantive research has been conducted on the use of the noun forms of shoulds and oughts. Nevertheless, the existence of musts has been acknowledged, with scholars tending to agree that it is usually used in the singular (i.e., "a must") in colloquial expressions referring to something that is so exciting, modern, or useful that everyone should want to see, listen to, or have it. The following examples have been described in dictionaries:

\begin{tabular}{ll}
\hline 3. & $\left(M E D^{2}\right)$ \\
(a) Good binoculars are a must for any serious birdwatcher & $\left(L D C E^{5}\right)$ \\
(b) Warm clothes are a must in the mountains & $\left(O A L D^{8}\right)$ \\
(d) If you live in the country a car is a must & $\left(C A L D^{4}\right)$ \\
\hline
\end{tabular}

As explained by Konishi (2006: 737), the noun form of must is used as an informal expression with an indefinite article to denote something that is definitely needed in a particular situation: Goggles are a must for skiing when it is snowing $(L A A D)$. As an adjective, must is used as a prefix, as in "this month's must-see film" $(M E D)$ and "the cashmere scarf is this season's must-have" (CALD). This form is in much less common usage than is the noun form "a must". It tends to be used primarily in colloquial forms and in journalism (original discussion in Japanese).

According to Ishibashi (1966: 267) "a must" originated in newspapers. Reporters used it in articles intended for publication in newspapers, and it eventually came into common usage as a noun (original discussion in Japanese). Ishibashi (1966) further cites examples of "no musts" and "musts", as found in the Oxford English Dictionary $(O E D)$. The following is one example (4):

4. In uttering these three terrible musts, Klesmer lifted up three long fingers in succession [G. Elliot: Daniel Deronda (OED); Ishibashi 1966: 267]

$O E D^{2}$ also describes the plural form, musts (defined as "necessary"; used in American English) as shown below (5).

5.

These valuable books are musts for you

(1957 R. Hoggart, Uses of Literacy x. 250)

A similar explanation is offered in $S O D^{6}$. Both $O E D^{2}$ and the $S O D^{6}$ describe should and ought as nouns, defining should as referring to what is right, sensible, or correct and ought as referring to the right or sensible thing to do, or the proper way to behave. 
Table 1 Auxiliary verbs

\begin{tabular}{lll}
\hline Root/present form & Past form & Types \\
\hline Can & Could & $\begin{array}{r}\text { Core modal auxiliary } \\
\text { (core modal verbs) }\end{array}$ \\
May & $\begin{array}{l}\text { Might } \\
\text { Should }\end{array}$ & \\
Shall & Would & \\
Will & n/a & \\
Must & n/a & \\
Ought to & narginal modals & \\
Used to & n/a & \\
Need & n/a & \\
Dare & & \\
\hline
\end{tabular}

4.2 Descriptions of auxiliary verbs: types of auxiliary verbs and modality

Table 1 contains a list of auxiliary verbs.

The auxiliary verbs listed in Table 1 are classified into two modalities: epistemic and root. Before defining these two specific modalities, it is important to provide a general definition of modality. In this study, I follow Sawada (2006: 3), who defines modality as a semantic category used to express a feeling or perception of an event or to describe what an event is or should be, but not to express whether an event is true.

To date, scholars have paid considerable attention to the classification of modality. ${ }^{7}$ This study proceeds from the most widespread and influential classifications in use since the late 1960s: epistemic modality and root modality. ${ }^{8}$

Epistemic modality concerns an estimation of the likelihood that a certain state of affairs (or some aspect thereof) is/has been/will be true (or false) in the context of the possible world under consideration. Root modality is concerned with applying attitudes to the world of things and social interaction.

The following table shows the functions of each auxiliary verb listed in Table 1 when classified according to epistemic modalities and root modalities (based on Aarts 2001: 282ff.; Jenkins 1972: 72f).

\section{Results}

\subsection{Quantitative and qualitative research}

Table 2 provides the noun forms of auxiliary verbs listed in Table 1. I investigated the frequency of each noun form using three corpora: the British National Corpus

\footnotetext{
7 von Wright (1951) classifies modality into five types from a logical viewpoint: alethic, epistemic, deontic, existential, and dynamic. Hofmann (1976) divides modality into root and epistemic. Halliday (1970) refers to modulation and modality, while Ota (1972) refers to cognitive and epistemic. Close (1975) classifies modality into primary and secondary; and Quirk and colleagues (1985) classify it into intrinsic and extrinsic, and Palmer (2001) classifies it into root and epistemic.

8 This classification has been adopted by Hofmann (1966), Perlmutter (1970), Jackendoff (1972), Ota (1972), Jenkins (1972), Coates (1983), Davidsen-Neilsen (1990), Sweetser (1990), Declerck (1991), Langacker (1991), Brennan (1993), Sawada (1975,1993, 1995) and Westney (1995).
} 
Table 2 Noun forms of auxiliary verbs listed in Table 1

\begin{tabular}{llll}
\hline Root/present form & Past form & Type & Noun form \\
\hline Can & Could & $\begin{array}{c}\text { Core modal auxiliary } \\
\text { (core modal verbs) }\end{array}$ & $\begin{array}{l}\text { A can, cans, a could, coulds } \\
\text { A may, mays, a might, mights } \\
\text { May }\end{array}$ \\
Might & Should & A shall, shalls, a should, shoulds \\
Will & Would & & A will, wills, a would, woulds \\
Must & n/a & Marginal modals & A must, musts \\
Ought to & n/a & A ought, oughts, ought to's \\
Used to & n/a & n/a \\
Need & n/a & & A need, needs \\
Dare & n/a & A dare, dares \\
\hline
\end{tabular}

Table 3 Frequency of each noun form in $\mathrm{BNC}, \mathrm{WB}$, and COCA

Singular forms (e.g., could) imply the frequency of both $a$ could and the could. The negative forms are not counted, as their frequency is quite low compared to that of the positive forms. This study treats the negative forms as an example

\begin{tabular}{lrrrr}
\hline & BNC & WB & COCA & Sum \\
\hline Could & 0 & 0 & 0 & 0 \\
Coulds & 0 & 1 & 6 & 7 \\
Shall & 0 & 0 & 0 & 0 \\
Shalls & 0 & 0 & 3 & 3 \\
Should & 2 & 0 & 0 & 2 \\
Shoulds & 8 & 7 & 33 & 0 \\
Would & 0 & 0 & 0 & 0 \\
Woulds & 0 & 0 & 0 & 1,510 \\
Must & 27 & 276 & 1,007 & 76 \\
Musts & 11 & 5 & 60 & 6 \\
Ought & 1 & 1 & 4 & 1 \\
Oughts & 7 & 2 & 22 & \\
Ought to's & 0 & 0 & & \\
\hline
\end{tabular}

(BNC), WordBanksOnline (WB), and the Corpus of Contemporary American English (COCA). ${ }^{9}$ The results are presented in Table 3. Please note that a/the can, cans, a/the may, a/the might, mights, a/the will, wills, a/the need, needs, and a/the dare have not been included, as they have established meanings as nouns. Needs and dares have also been excluded, as they function as verbs.

Examples (6)-(13) refer to noun forms observed in Table 3 [(6) is coulds, (7) is shalls, (8) a should, (9) shoulds, (10) a ought, (11) oughts, (12) ought to's, and (13) musts].

As shown in Table 3, with the exception of a/the must, musts, and ought to's, plural forms (e.g., shalls) and past plural forms (e.g., coulds, shoulds, and oughts) appear with greater frequency than do singular present forms. This is because the marker-(e)s added to these forms clearly indicates that the auxiliary verb is operating as a noun. The past forms of auxiliary verbs are used more often because

\footnotetext{
$\overline{9}$ I accessed the corpora on Feb. 16 and 19, 2014.
} 
Table 4 Functions of auxiliary verbs in each modality

\begin{tabular}{|c|c|c|}
\hline & Root modality & Epistemic modality \\
\hline Can, could & Ability, neutral possibility, and existential meaning & $\begin{array}{l}\text { Possibility, knowledge-based } \\
\text { conclusion (in negatives) }\end{array}$ \\
\hline May, might & Permission & Knowledge-based supposition \\
\hline Shall & $\begin{array}{l}\text { Supposition, rules, obligation, volition, asking for } \\
\text { direction }\end{array}$ & Futurity \\
\hline Should & Necessity & Evidence-based supposition \\
\hline Will, would & Volition, tendency, obligation & $\begin{array}{l}\text { Necessity, evidence-based } \\
\text { predictions/conclusions }\end{array}$ \\
\hline Must & $\begin{array}{l}\text { Obligation, a property necessarily attributable to a } \\
\text { subject-referent, necessity }\end{array}$ & Knowledge-based conclusion \\
\hline Ought to & Necessity & $\mathrm{n} / \mathrm{a}$ \\
\hline Used to & Habitual situation in the past & $\mathrm{n} / \mathrm{a}$ \\
\hline Need & Necessity & $\mathrm{n} / \mathrm{a}$ \\
\hline Dare & Forward-looking & $\mathrm{n} / \mathrm{a}$ \\
\hline
\end{tabular}

they are able to convey the core function of each auxiliary verb used as a root modality, as shown in Table 4 (e.g., obligation, in the case of $m u s t$ ), without leading to semantic or syntactic misunderstanding. For example, in (6a), maybes (53 instances in COCA) is observed before coulds. Similarly, shalls and shoulds appear together in (7a) and (7b). As demonstrated by example (8), similar noun forms (e.g., $a$ want and $a$ must) are used around $a$ should.

Nouns that do not appear in the corpora (e.g., a could and $a$ would) function as quotation substantives, as in "a could-be leader of his country" and "(a) would-be writer Nick Carrway arrives in NYC in 1922, an era of loosening morals, glittering jazz and bootleg kings". As explained by Jesperseon (1913), the quotation substantive is a linguistic phenomenon in which a word or phrase is treated as a nominal, even if that was not its original function. The quotation substantive is occasionally indicated by quotation marks or hyphenation (e.g., "love played at catch-me-if-you-can”).

6. (a) Castilla held up a hand. "We've been over this before, Larry. I'm not going to keep an entire country in the Dark Ages over a bunch of maybes and coulds..." (COCA, written, 2011)

(b) There was a lot of (complaining) going on. It was like you couldn't make a mistake without being ridiculed. There were too many can'ts instead of coulds. (COCA, spoken, 1999)

7. (a) Characters in his novels also show an awareness of language. In Farewell, My Lovely, the soon-to-be-murdered Lindsay Marriott, using shalls and shoulds in a formal way, takes offense at Marlowe's saying he's not particular about his job "as long as it's legitimate" (COCA, written, 2005)

(b) Fully conforming implementation of the IEEE standard (all of the "shalls" and most of the "should"). Full support for both single and double formats (COCA, written, 1999)

8. (a) "It needs to be a want, not a should", says psychiatrist Tracy Latz, M.D., coauthor of Shift: 12 Keys to Shift Your Life, who uses affirmations in her North Carolina practice (COCA, written, 2009) 
(b) BOAZ: It might very well (sic. It might be very well). You know, they start out saying, it's just a should, and then they say, OK, it's a must (CROSSTALK) (COCA, spoken, 2002)

9. (a) We can preach about the shoulds and should nots of sexual morality. And we can certainly say a lot about abstinence, denial, and sublimation (COCA, written, 2004)

(b) What your skills are, what your abilities are, what you love. Doing what's right for you, not your shoulds and your musts (COCA, spoken, 2006)

10. (a) The bond of marriage creates "a moral ought inherent in the marriage union". (n104) That "ought" is the moral obligation to keep one's promises, to follow through on one's commitments. The ought is due to the person to whom the commitment is made and so is an interpersonal obligation, but the obligation is more complex because it is more than interpersonal (COCA, written, 2004)

(b) Tell me what is required to make one a better functioning human being, a better neighbor, and a more fully actualized person in a sustainable society and I shall know the ought (COCA, written, 2000)

11. (a) SCARF: It's a family that's filled with what I call 'shoulds' and 'oughts'. They do what they should do, what they ought to do, not what they would like to do... (COCA, spoken, 1995)

(b) Kernis contends that we each acquire a mixed set of should, oughts, and have-to's while still too young to process them (COCA, written, 2008)

(c) .... "I don't like my life," and then we would say, "Yeah, but that wouldn't induce you to commit suicide. What else are you telling yourself?" And that's when clients say things like, "It shouldn't be the way it is. It's terrible that I failed. I'm no good". That is when we hear the shoulds, the oughts and the musts, and then we convince the client to abandon these irrational demands... (COCA, written, 2001)

(d) They should be more committed, more disciplined and better organized in their prayer life. They ought to try harder. It took me a while to pick up the "shoulds" and "oughts" in these confessions (COCA, written, 1993)

(e) The core of neurotic emotions can be found in people's tendencies to take their strong rational preferential thoughts for success, approval, and comfort and escalate them to absolute necessities: shoulds, oughts, demands, or musts. Irrational beliefs lead to disturbed emotional states such as depression, panic, despair, or anger (COCA, written, 1990)

12. Dr-McGRAW:... what I want people to do when you're in these relationships is stop using 'and start measuring it based on results. If it's working, you do it. If it's not, you don't. Measure 'shoulds' and 'must' and 'ought to's' what you're doing based on results... (COCA, spoken, 2001)

13. (a) They were telling themselves, "I absolutely must be loved by the person I love or I am no good as a person". And I started pointing out their irrational demands and disputing their shoulds and musts, and some of them got remarkably better quite quickly (COCA, written, 2001)

(b) Days I am dizzy with activity, and nights, dazed with exhaustion, I hunger for more musts and have-to's.... (COCA, written, 1996)

(c) Ask yourself, What are my needs and values? What factors in my life are nonnegotiable? What are musts for my happiness in life and at work? (COCA, written, 2006)

The noun forms of each auxiliary verb exemplified in examples (6)-(13) belong to the central function of the root modality shown in Table 4. This means that the central functions of the auxiliary verbs as root modalities are used metalinguistically when their noun forms appear within these contexts. The noun forms in these examples can be classified into three types. In Type 1, the noun forms of auxiliary verbs are quoted as part of the expression of a single speaker. In Type 2, they are used to quote a provision. Finally, in Type 3, they function entirely as 
Table 5 Three types of noun forms and their syntactic patterns

\begin{tabular}{lll}
\hline Type & Syntactic patterns & Examples \\
\hline 1 & The + noun forms & $(7 \mathrm{a}),(11 \mathrm{c}, \mathrm{d})$ \\
& $\varphi+$ noun forms & \\
2 & The + noun forms & $(7 \mathrm{~b}),(9 \mathrm{a}),(10 \mathrm{a}, \mathrm{b})$ \\
3 & $\mathrm{~A}+$ noun forms & $(6 \mathrm{a}, \mathrm{b}),(8 \mathrm{a}, \mathrm{b}),(9 \mathrm{~b}),(11 \mathrm{a}, \mathrm{b}, \mathrm{e}),(12),(13 \mathrm{a}, \mathrm{b}, \mathrm{c})$ \\
& $\varphi+$ noun forms & \\
& Possessive + noun forms & \\
\hline
\end{tabular}

nouns. In Table 5, the noun forms shown in examples (6)-(13) are classified into the following three types.

Examples of Types 1 and 2 are quite clear. The Type 1 noun forms in example (7a)_shalls and shoulds-appear several times in the utterances of Lindsay Marriott. In this case, shall and should are used in their plural forms. The Type 2 noun forms in example (9a), shoulds and should nots, appear in a quotation from a preacher, in reference to a necessary provision for sexual morality. Similarly, the ought in example (10a) demonstrates the objective necessity caused by the event or marriage.

As shown in examples (9), (11), (12), and (13), the patterns shoulds and oughts, shoulds and should nots, shoulds and musts, shoulds and must and ought to's, and should/oughts/musts and have-to's (have-to's is observed twice in COCA) appear more frequently in corpora than do shoulds, oughts, and musts in independent usage. Some patterns (e.g., do's and don'ts) constitute PUs due to their high frequency. It is important to note, however, that the lexical meaning of each noun form has survived, although should, ought, and must have been joined together in a PU.

Although they serve the same function (i.e., obligation), there are important differences between should, ought, must, and have to. These differences should be addressed before considering the functions of the following examples: (9b) your shoulds and your musts, (11a) shoulds and oughts, (11b) should, oughts, and haveto's, (11c) the shoulds, the oughts, and the musts, (11d) shoulds and oughts, (11e) shoulds, oughts, demands, or musts, (12) shoulds and must and ought to's, (13a) shoulds and musts, and (13b) musts and have-to's. The features of should, ought, must, and have to are summarized in (14)

\footnotetext{
14. (a) Should, must subjective obligation/compulsion, which a speaker considers obligatory

(b) Ought to, ought, have to objective obligation, which a speaker acts by a surrounded situation or event
}

Based on explanations provided in (14), the characteristics of should, ought, must, and have to are detailed in (15), with reference to the addresser, addressee, event, or situation. 


\begin{tabular}{lll}
\hline 15. & Should & Addresser $\rightarrow$ addressee (subjective obligation) \\
(b) & Ought to/ought & Event, situation $\rightarrow$ addressee (objective obligation) \\
(c) & Must & Addresser $\rightarrow$ addressee (subjective compulsion) \\
& & Addresser $\rightarrow$ addresser (subjective obligation) \\
(d) & Have to & Event, situation $\rightarrow$ addressee (objective obligation)
\end{tabular}

As represented in (15), each word has its own features, despite the apparently similar functions or obligations shared by all of them.

The consideration concerning the noun forms of auxiliary verbs above suggests that the noun forms of each auxiliary verb are used semantically to reflect the core function of the verb, classified into root modality (as explained in Table 4). This implies that the meta-linguistic functions of each noun form emerge semantically. The meta-linguistic functions of each noun form are explained in (16).

\begin{tabular}{ll}
\hline 16. & Coulds-ability \\
(b) & Shalls—supposition \\
(c) & A/the should/shoulds—subjective obligation \\
(d) & A must/must—subjective obligation \\
(e) & Ought to/an ought/oughts—objective obligation
\end{tabular}

As shown in (16), auxiliary verbs that function as obligations tend to have been used as a noun form. This has something to do with the analogy of a must. It (functioning as an obligation) has already been established as a noun, and semantically similar auxiliary verbs (e.g., should, ought, and ought to) have come to behave like nouns by emulating a must. At this point, it is important not to confuse the differences between the noun forms functioning as obligation, as shown in (16).

The point of this discussion is that the noun forms of auxiliary verbs emerge when they do not cause semantic confusion and when they are used as past or plural forms. In addition, the noun forms of auxiliary verbs provide a semantic reflection only of the root modality.

5.2 The difference between "a" and "the" co-occurring with the noun forms of auxiliary verbs

Table 6 lists the number of times that the noun forms of auxiliary verbs co-occur with either an indefinite article or a definite article in the corpora $\mathrm{BNC}, \mathrm{WB}$, and COCA.

As represented in Table 6, the pattern "a + noun forms" appears more frequently than does the pattern "the + noun forms" when must and should are used in singular forms. Conversely, the pattern "the + noun forms" appears more 
Table 6 Frequency of the patterns "a + noun forms of auxiliary verbs" and "the + noun forms of auxiliary verbs" observed in BNC, WB, and COCA

\begin{tabular}{lcccr}
\hline Noun forms & A + noun forms & The + noun forms & Others ${ }^{\mathrm{a}}$ & Sum \\
\hline Coulds & 0 & 2 & 5 & 7 \\
Shalls & 0 & 1 & 0 & 3 \\
Should & 2 & 0 & 0 & 2 \\
Shoulds & 0 & 18 & 30 & 48 \\
Must & 1,505 & 6 & 0 & 1,510 \\
Musts & 0 & 6 & 70 & 76 \\
Ought & 0 & 3 & 0 & 6 \\
Oughts & 0 & 28 & 31 \\
\hline
\end{tabular}

a This category includes the patterns "zero article + noun forms of auxiliary verbs" and "possessive forms + noun forms of auxiliary verbs"

frequently than does the pattern "a + noun forms" for noun forms other than must and should.

The pattern "a + noun forms" (e.g., a should and a must) implies an obligation mentioned for the first time by a speaker in a given context, and causes no semantic confusion when appearing alone within the context. This is why a must is already known as an established noun. As shown in example (8a), however, $a$ want precedes a should and, in example (8b), a must precedes $a$ should. This example implies that the noun form $a$ should is less familiar compared to a must, so similar noun forms (e.g., a want or a must) thus appear around $a$ should. More specifically, the noun forms of auxiliary verbs become established as nouns when the syntactic pattern "a + noun form" is used.

On the other hand, the ought in example (10), which is caused by marriage, implies an obligation that has already been referred to as the quotation of a provision. For this reason, the pattern "the + noun forms" is used. This suggests that the pattern "the + noun forms" is adopted when the noun forms of auxiliary verbs refer to the quotation of a provision, as shown in Table 5. In other words, the pattern is a precursor to the establishment of the noun forms of auxiliary verbs as nouns. Moreover, as shown in Table 6, plural forms tend to co-occur with either zero articles or possessive forms, implying that plural noun forms are independently established as nouns. Possessive forms tend to be used to indicate the semantic belongingness of the noun forms of auxiliary verbs.

\subsection{Investigation into registers of American and British English regarding} the appearance of noun forms of auxiliary verbs

Table 7 shows the manner (i.e., spoken or written) in which many noun forms of auxiliary verbs appear in the two registers.

As discussed in Sect. 4.1, Ishibashi (1966) observes that a must is used primarily in newspapers. The results presented in Table 7 partly support this observation. If we focus on the high-frequency noun forms listed in Table 7 (i.e., shoulds, a must, 
Table 7 Frequency and percentage of noun forms of auxiliary verbs in each register

The number of words in each register is as follows: written is $508,056,986$ and spoken is $120,583,410$

Table 8 Frequency and percentage of noun forms used in American and British English

The number of words used in British English is 153,138,713 and that of American English is $470,513,833$

\begin{tabular}{lll}
\hline & Written $(\%)$ & Spoken $(\%)$ \\
\hline Coulds & $5(0.000001)$ & $2(0.000002)$ \\
Shalls & $3(0.0000006)$ & $0(0)$ \\
A should & $2(0.0000004)$ & $0(0)$ \\
Shoulds & $45(0.000009)$ & $3(0.000002)$ \\
A must & $1,391(0.003)$ & $119(0.0001)$ \\
Musts & $73(0.00001)$ & $3(0.000002)$ \\
A ought & $6(0.000001)$ & $0(0)$ \\
Oughts & $29(0.000006)$ & $2(0.000002)$ \\
Ought to's & $0(0)$ & $1(0.0000008)$ \\
Sum & $1,554(0.003)$ & $130(0.0001)$ \\
\hline
\end{tabular}

\begin{tabular}{lll}
\hline & British English $(\%)$ & American English $(\%)$ \\
\hline Coulds & $1(0.0000006)$ & $6(0.000001)$ \\
Shalls & $1(0.0000006)$ & $2(0.0000004)$ \\
A should & $1(0.0000006)$ & $1(0.0000002)$ \\
Shoulds & $10(0.000006)$ & $38(0.000008)$ \\
A must & $501(0.0003)$ & $1,009(0.0002)$ \\
Musts & $16(0.00001)$ & $60(0.00001)$ \\
A ought & $2(0.000001)$ & $4(0.0000008)$ \\
Oughts & $9(0.000006)$ & $22(0.000004)$ \\
Ought to's & $0(0)$ & $1(0.0000002)$ \\
Sum & $541(0.0004)$ & $1,143(0.0002)$ \\
\hline
\end{tabular}

and musts) and investigate their frequency in the two registers, the result is written $>$ spoken.

In the following section, I draw upon the corpora to consider whether the noun forms of auxiliary verbs are specific to American usage. The results are summarized in Table 8. Unlike the explanation made in the $O E D^{2}$, the noun forms of auxiliary verbs appear commonly both in American English and in British English.

\subsection{Core modal auxiliaries and marginal modals}

Table 9 shows the frequency of noun forms in core modal auxiliaries and marginal modals.

The reason for the much greater use of core modal auxiliaries as noun forms (as compared to marginal modals) has to do with the number of the noun forms used as core modal auxiliaries. 
Table 9 Frequency of noun forms in core modal auxiliaries and marginal modals

\begin{tabular}{llr}
\hline Core modal auxiliaries (\%) & Marginal modals (\%) & Sum \\
\hline $1,646(97.7)$ & $38(2.3)$ & 1,684 \\
\hline
\end{tabular}

\section{Dictionary definition of 'shoulds and oughts', 'oughts, and musts', 'shoulds and musts', and 'musts and have to's'}

The previous sections have identified the functions of the PUs using the inductive method. In (17), I propose my own definition of 'shoulds and oughts', 'oughts, and musts', 'shoulds and musts', and 'musts and have to's' on the basis of above observations.

17. Phrase Shoulds and oughts used to say a speaker's obligation to a listener and an obligation caused by an event or a situation to a listener

Oughts and musts used to say an obligation caused by an event or a situation to a listener and a speaker's obligation to his/herself

Shoulds and musts used to say a speaker's obligation and compulsion to a listener

Musts and have to's used to say a speaker's obligation to his/herself and an obligation caused by an event or a situation to a listener

All PUs work as a noun in sentences although they comprise functions words. In other words, PUs composed by two auxiliary verbs cause degrammaticalization.

\section{Peripheral phenomena}

In this section, I discuss whether have to's, maybes, haves, 'haves and have nots', want to's, ifs, ands, buts, and similar expressions have become established as nouns.

\subsection{Have to's}

According to Jenkins (1972), have to functions as obligation, as its root modality and its function are retained when have to is transformed into the noun form (i.e., have to's). COCA contains only two examples of have to's (as shown below).

18. (a) .... Well, it's time to get moving! Here's why: When your day-to-day existence gets packed with too many "have to's" and not enough "want to's," you can end up with a constant, low-grade "Is this all there is?" kind of fever... (COCA, written 2007)

(b) MR-PETERSON: every event becomes a little more important, every holiday, because you don't know if you're going to have another one. You sort of start out thinking, you know, what are the minimums, what are, you know, what do I have to do, and one of the have to's was to make it to get Mark out of high school (COCA, spoken, 1990) 
Table 10 Patterns as noun forms, and their frequency observed in COCA, BNC, and WB

\begin{tabular}{lccr}
\hline & COCA & BNC & WB \\
\hline Maybes & 53 & 6 & 6 \\
Haves & 558 & 45 & 36 \\
Have nots & 73 & 0 & 0 \\
Haves and have nots & 16 & 0 & 0 \\
The haves and the have nots & 11 & 0 & 0 \\
Want to's & 1 & 0 & 0 \\
Ifs & 506 & 53 & 54 \\
Buts & 182 & 47 & 38 \\
Ands & 120 & 12 & 12 \\
\hline
\end{tabular}

In example (18), "have to's" operates as a noun implying obligation, and the similar noun form "want to's" is preceded by "have to's" in example (16a).

\subsection{Others}

Table 10 provides the noun forms found in COCA, BNC, and $\mathrm{WB}$ and their frequency in the corpora. Examples (19)-(24) include maybes, have nots, 'haves and have nots', and 'the haves and the have nots', and 'no ifs, ands, or buts', respectively [for want to's, see example (18a)]. As illustrated in the following examples, all of these expressions behave like nouns.

19. "We were in East Texas', his ex-wife Josie Odoms said of the day of the crime". That is the only thing that I know and stake my life on. There's no ifs and maybes about it....(COCA, written, 2007)

In example (19), the expression maybes indicate that something might happen or might be true, although the speaker is not certain.

20. As Republicans our first concern is for those waiting tonight to begin or resume the climb up life's ladder. We do not accept that ours will ever be a nation of haves and have nots. We must always be a nation of haves and soon-to-haves (COCA, written, 2012)

21. SCOTT-PELLEY: another thing facing the country right now is income disparity. There has never been a wider gap between the haves and the have nots. How do you see that? (COCA, spoken, 2011)

Examples (20) and (21) show that (the) haves and (the) have nots tend to be used together and that the phrase (e.g., gap, difference) between (the) haves and (the) have nots often appears in corpora. It is used to refer to the rich and poor people in a country or society. As demonstrated in examples (22) and (23), haves refers to rich 
or advantaged people, while have nots refer to poor or disadvantaged people. These expressions have their own established meaning as nouns.

22. And you and I, Mister Stein, are extremely lucky to be paid for a subjective asset: our talent. I have always understood that the "haves" were greedy (COCA, spoken, 2010)

23. Indeed, in the form of sharing which is the most commonly practiced among hunter-gatherers, and which has been called "demand-sharing" (Peterson 1993), the "have nots" demand that the "haves" share with them. That is to say, the "have nots" are not passive recipients; on the contrary, they initiate the giving and, in a sense, orchestrate it (COCA, written, 2008)

Example (24) indicates that ifs, ands, and buts are used together into the phrase no ifs, ands, or buts, which means that no excuses are to be tolerated.

24. (a) HAMMER: moving on tonight, there's more SHOWBIZ trending on SHOWBIZ TONIGHT. Here's what's coming up at the bottom of the hour. It's the great royal rump debate. Did Pippa Middleton pad her butt for the royal wedding? Some are saying there are no ifs, ands or buts about it. And the big Kardashian wedding countdown is on (COCA, spoken, 2011)

(b) Snoot sat down gratefully. Had room to think in the woods, "he said, "and I can tell you this, no ifs, ands, or buts: Frounce was the best big-bosomed redheaded woman ever put on God's green earth" - he spoke to the ceiling —-and that's the truth of it (WB, written, 1990)

\section{Conclusion}

In this paper, I use both quantitative and qualitative analysis to describe auxiliary verbs that are used as nouns. The noun forms of auxiliary verbs imply the core function of auxiliary verbs as their root modality. In other words, the noun forms are used meta-linguistically. Moreover, two noun forms of auxiliary verbs (i.e., shoulds and musts) are frequently observed, and they have been established as independent PUs. The meanings of PUs consist of the sum of the functions of each component as a root modality. The study also discusses new noun forms (e.g., maybes, want to's) that have been observed in corpora. These cases reflect the same characteristics as those identified in the noun forms of auxiliary verbs.

\section{Corpora}

BNC: British National Corpus.

COCA: the Corpus of Contemporary American English.

WordBanksOnline. 


\section{Dictionaries}

CALD ${ }^{4}$ : Cambridge Advanced Learner's Dictionary. 4th edition. 2013. Cambridge: Cambridge University Press.

LDCE $E^{5}$ : Longman Dictionary of Contemporary English. 5th edition. 2008. London: Longman.

MED ${ }^{2}$ : Macmillan English Dictionary. 2nd edition. 2007. Oxford: Macmillan Education.

OALD ${ }^{8}$ : Oxford Advanced Learner's Dictionary. 8th edition. 2010. Oxford: Oxford University Press.

OED: Oxford English Dictionary. 1928. Oxford: Oxford University Press.

$O E D^{2}$ : Oxford English Dictionary. 2nd edition. 2009. CD-ROM version 4.0.

Oxford: Oxford University Press.

SOD ${ }^{6}$ : Shorter Oxford English Dictionary. 6th edition. 2007. CD-ROM version 3.0.

Oxford: Oxford University Press.

\section{References}

Aarts, B. 2011. Oxford Modern English Grammar. Oxford: Oxford University Press.

Biber, D., S. Johansson, G. Leech, S. Conrad, and E. Finegan. 1999. Longman Grammar of Spoken and Written English. London: Longman.

Brennan, V.M. 1993. Root and epistemic modal auxiliary verbs. Doctoral dissertation submitted to University of Massachusetts.

Burger, H., D. Cobrovol'skil, P. Kühn, and N.R. Norrick. 2007. Phraseology: an international handbook for contemporary research. Berlin: Walter de Gruyter.

Close, R.A. 1975. A reference grammar for students of English. London: Longman.

Coates, J. 1983. The semantics of the modal auxiliaries. London: Croom Helm.

Cowie, A.P. 1998. Phraseology: theory, analysis, and applications. Oxford: Clarendon Press.

Davidsen-Neilsen, N. 1990. Tense and mood in English: a comparison with Danish. Berlin: Mouton de Gruyter.

Declerck, R. 1991. A comprehensive descriptive grammar of English. Tokyo: Kaitakusha.

Halliday, M.A.K. 1970. Functional diversity in language as seen from a consideration of modality and mood in English. Foundations of Language 6: 322-361.

Hofmann, T.R. 1966. Past tense replacement and the modal system. National Science Foundation 17-VII:1-21.

Hofmann, T.R. 1976. Past tense replacement and the modal system. Syntax and Semantics 7: 85-100.

Howarth, P.A. 1998. The phraseology of learners' academic writing. In Phraseology: theory, analysis, and applications, ed. A.P. Cowie, 161-186. Oxford: Clarendon Press.

Inoue, A. 2007. Present-day spoken English: a phraseological approach. Tokyo: Kaitakusha.

Inoue, A. 2014. Actual behaviors of newly observed phraseological units comprising two prepositions. International Journal of English Linguistics 4(4): 74-87.

Ishibashi, K. (ed.). 1966. A dictionary of current English usage. Tokyo: Taishukan Syoten.

Jackendoff, R. 1972. Semantic interpretation in generative grammar. Cambridge: MIT Press.

Jenkins, L. 1972. Modality in English syntax. Doctoral dissertation submitted to Massachusetts Institute of Technology.

Jesperseon, O. 1913. A modern English grammar on historical principles PART II SYNTAX. London: Allen \&Unwin.

Konishi, T. (ed.). 2006. Sanseido's dictionary of present-day English usage. Tokyo: Sanseido.

Langacker, R.W. 1991. Foundations of cognitive grammar, vol. 1. Redwood City: Stanford University Press. 
Leech, G., M. Hundt., C. Mair, and N. Smith. 2009. Change in contemporary English: a grammatical study. Cambridge: Cambridge University Press.

Mair, C., and G. Leech. 2006. Current change in English syntax. In The Handbook of English Linguistics, ed. B. Aarts, and A. McMahon, 318-342. Oxford: Blackwell Publishing Ltd.

Ota, A. 1972. Modals and some semi-auxiliaries in English. The ELEC (English Language Education Council) Publications. 9: 42-68.

Palmer, F.R. 2001. Mood and modality. Cambridge: Cambridge University Press.

Perlmutter, D. 1970. The two verbs begin. In Readings in English transformational grammar, ed. R.A. Jacob, and P.S. Rosenbaum, 107-119. Waltham: Blaisdell Publishing Company.

Peterson, N. 1993. Demand sharing: Reciprocity and the pressure for generosity among foragers. American Anthropologies 95(4): 860-874.

Quirk, R., S. Greenbaum. G. Reech, and J. Svartvik. 1985. A comprehensive grammar of the English language. London: Longman.

Sampson, G.R. 2001. Empirical linguistics. London: Continuum.

Sawada, H. 2006. Modality. Tokyo: Kaitakusha.

Sawada, H. 1975. Nihongo syukanteki doushi no koubun teki kousatu—tokuni 'hyougensei' wo tsyuushin to shite-(A constructional study of subjective verbs in Japanese-centered on expressivity). Gengo Kenkyuu (Linguistic Study) 68: 75-103.

Sawada, H. 1993. Shiten to Syukansei-Nichi Eigo Jydoushi no Bunseki (Point of view and subjectivityanalysis on auxiliary verbs in Japanese and English). Tokyo: Hitsuji Syobou.

Sawada, H. 1995. Studies in English and Japanese auxiliaries: a multi-stratal approach. Tokyo: Hitsuji Syobou.

Sinclair, J. 1991. Corpus, concordance, collocation. Oxford: Oxford University Press.

Sweetser, E. 1990. From etymology to pragmatics. Cambridge: Cambridge University Press.

von Wright, G.H. 1951. An essay in modal logic. Netherlands: Amsterdam.

Westney, P. 1995. Modals and periphrastic in English. Tübingen: Max Niemeyer Verlag.

Widdowson, H.G. 1989. Knowledge of language and ability for use. Applied Linguistics 10-2: 128-137. Willis, D. 2003. Rules, patterns and words: grammar and Lexis in English language teaching (Cambridge Language Teaching Library). Cambridge: Cambridge University Press. 